\title{
AS CLASSES MÉDIAS EM PORTUGAL: QUEM SÃO E COMO VIVEM \\ [João Miguel Teixeira Lopes, Francisco Louçã e Lígia Ferro, 2019, Lisboa, Bertrand]
}

\author{
Pedro Abrantes \\ Universidade Aberta \& Iscte - Instituto Universitário de Lisboa, Centro de Investigação e \\ Estudos de Sociologia (CIES-Iscte), Lisboa, Portugal
}

As Classes Médias em Portugal completa a trilogia iniciada com Os Burgueses (2014) e que incluiu igualmente As Classes Populares (2017), obras publicadas na mesma editora e que contaram igualmente com João Miguel Teixeira Lopes e Francisco Louçã como autores (Lígia Ferro participou na segunda, mas não na primeira publicação).

Num contexto de grande fragmentação temática como é o das ciências sociais portuguesas, existe, portanto, uma relevância acrescida nesta obra que, ao ser lida em conjunto com as duas anteriores, reconstitui de certa forma uma visão panorâmica e de "grande fôlego" sobre a estrutura de classes no Portugal contemporâneo, um pouco à semelhança da famosa trilogia produzida por C. Wright Mills (2001 [1948], 1951 e 1956), sobre as classes sociais norte-americanas.

Além disso, trata-se possivelmente da obra mais original e ambiciosa desta série, uma vez que se regista na sociologia portuguesa alguma escassez de estudos sobre as classes médias, resultado de um alargado ceticismo quanto à pertinência deste conceito que se tornou corrente no senso comum sobre as sociedades modernas. Os autores não escondem, aliás, partilhar deste ceticismo, colocando a própria adequação do conceito (no singular ou no plural), não como um dado adquirido, mas como uma questão central do estudo, tanto no plano teórico como na análise empírica. Em termos sociológicos, existirá efetivamente uma classe média? Ou várias? Se sim, como defini-la e delimitá-la? Em que se distingue das restantes? Se não, como explicar a omnipresença do conceito nos discursos sobre as sociedades modernas e nas próprias autorrepresentações de uma grande parte das populações?

Nos capítulos 1 e 5, a obra providencia uma excelente revisão da literatura internacional sobre o tema, recuperando obras clássicas e ponderando contributos recentes, discutindo virtudes e limitações de diferentes perspetivas teóricas e linhas de investigação, organizando-as em quatro posicionamentos distintos: os autores que não reconhecem a existência objetiva desta classe (concebendo-a fundamentalmente enquanto uma construção ideológica); aqueles que a definem apenas enquanto espaço (plural, contraditório e transitório) de posicionamentos híbridos; aqueles que a reconhecem pelos seus défices (basicamente, a carência de elementos que caracterizam a burguesia ou o proletariado); e, por fim, aqueles que defendem "a existência autónoma, a um mesmo tempo teórica e real, das classes médias" (p. 146).

Nos capítulos intermédios, não incluindo uma recolha original de dados, o estudo sintetiza e discute um conjunto diversificado de dados empíricos que resultam de investigações sobre a sociedade portuguesa, ao longo das últimas 
décadas. Contudo, nem essa revisão é exaustiva, nem é suficientemente orientada pelo referido quadro teórico (até porque os estudos de base que fornecem os dados partem de quadros teóricos muito distintos), o que fragiliza a argumentação. Frequentemente, a análise acaba por se centrar na sociedade portuguesa como um todo, não especificamente na classe média, e os dados vão sendo analisados através de tipologias muito variadas, o que dificulta uma reflexão mais sistemática e aprofundada sobre a questão. O recurso a dados organizados por quintis de rendimento, por exemplo, a partir de relatórios internacionais recentes, tem uma relação bastante problemática com a linguagem sociológica que tende a conceber as classes sociais como elementos de uma estrutura de relações socioprofissionais. No caso da educação, é pouco compreensível o enfoque nos colégios de elite e nos territórios educativos de intervenção prioritária, uma vez que, a existirem, as classes médias dificilmente serão encontradas nestes dois contextos "polarizados". Sendo utilizados de forma privilegiada os dados estatísticos, também há o recurso a algumas "caixas de texto" com narrativas biográficas que, sendo interessantes per se, sem serem explícitos os mecanismos de seleção dos casos e de recolha e tratamento dos dados, funcionam apenas como ilustrações de alguns dos principais argumentos.

Sendo mais específico, tendo como base as duas principais linhas de investigação sobre classes sociais em Portugal, a de Coimbra (Estanque e Mendes, 1997; Estanque, 2012) e a do CIES-IUL (e.g. Almeida, Costa e Machado, 1994; Machado e Costa, 1998; Costa e Mauritti, 2018), o capítulo 2 coloca o enfoque num conjunto de transições no plano económico e social, nomeadamente: (i) a urbanização; (ii) o acesso à propriedade, no âmbito da habitação; (iii) as mutações no comércio; (iv) a industrialização; (v) a distribuição de rendimentos; (vi) a massificação da escolaridade e do acesso às qualificações; e (vii) a expansão das profissões liberais e dos especialistas com formação superior. O argumento central parece ser o seguinte: embora estes vários processos tenham criado condições para a afirmação de classes médias, tal como tem ocorrido em matizes, ritmos e intensidades variadas em muitas outros países, em Portugal, os seus contornos não deixam de produzir uma relativa "magreza" e "vulnerabilidade" - ou "precariedade", conceito omnipresente ao longo da obra e que é frequentemente apresentado como um processo muito intensificado com a crise económica e as políticas de austeridade do período entre 2008 e 2015 - destas classes (em comparação com o observado noutras sociedades europeias).

O capítulo 3 discute o papel das classes médias nas transformações políticas, ao longo do último século, em Portugal, analisando quatro movimentos específicos: a implantação da República, no início do século XX, o movimento fascista dos anos 1920 e 1930, os movimentos estudantis dos anos 1960 e 1970 e as ações contestatárias do período da crise económica, nomeadamente entre 2008 e 2015. Há uma reflexão interessante sobre o modo como o "novo espírito do capitalismo" incorporou, em parte, as reivindicações libertárias dos movimentos dos anos 1960 e 1970, de forma a expandir-se, e outra sobre as novas configurações contestatárias dos últimos anos. Não existindo propriamente uma síntese conclusiva, a ideia de fundo parece ser a de que, embora certas frações das classes médias tenham desempenhado um papel muito relevante - nomeadamente frações mais jovens, em situação mais precária, mas com 
maiores recursos culturais e qualificacionais -, também é certo que nunca esta classe se mobilizou como tal. Tratou-se, portanto, de movimentos interclassistas, sendo possível identificar segmentos das classes médias mobilizados, nestes momentos de grande conflitualidade, tanto para posições mais progressistas ou até mesmo revolucionárias, como em torno de posições mais conservadoras.

O capítulo 4 analisa o conceito de classes médias no espaço dos gostos, dos estilos de vida e das práticas e consumos artísticos, em Portugal, tendo como forte inspiração o trabalho de Pierre Bourdieu (1979) sobre a sociedade francesa. Neste capítulo, um dos argumentos centrais é que, se as classes médias são caracterizadas por uma grande heterogeneidade (e heteredoxia) de práticas culturais, adotando estas um "carácter omnívoro", as fragilidades económicas, o pouco investimento da escola pública na educação artística e as recentes dificuldades no acesso a habitação nos centros urbanos têm criado sérios entraves a práticas culturais mais enriquecedoras, cultivadas e assíduas, sendo predominantes os consumos massificados - por exemplo, da televisão ou dos centros comerciais. Com base no trabalho etnográfico de Lígia Ferro, este capítulo inclui uma secção final de grande pertinência sobre o papel das classes médias na afirmação de novos movimentos culturais urbanos (como é o caso do hip-hop, do grafitti e do parkour), criando espaços de cruzamento interclassista ou mesmo de crítica à estrutura de classes.

Por seu lado, o facto de a revisão teórica ser sistematizada após a análise dos dados empíricos (capítulo 5) convidaria a que, nesse capítulo, se utilizassem as observações empíricas para discutir as virtudes e limitações da aplicação dos diferentes quadros teóricos à compreensão da sociedade portuguesa contemporânea, caminho que acaba por não ser trilhado.

Nas conclusões, os autores fazem um esboço "prudente" de uma posição que resulta das discussões teóricas e das análises empíricas apresentadas ao longo da obra. Nesta perspetiva, denotam a adesão a uma definição afirmativa das classes médias (em contraste, por exemplo, com a linha neomarxista), reconhecendo as suas possibilidades de formação, mobilização, fechamento e reprodução. Contudo, observam igualmente as tendências de heterogeneização e de polarização que limitam, em grande medida, a sua afirmação enquanto classe, a par das segmentações internas relativas a fatores como o género, a idade ou a etnia. Destacam ainda as classes médias enquanto espaço privilegiado de trânsitos, mobilidades e singularidades, exacerbado por uma ideologia dominante que, "sob o manto diáfano da individualização", a tende a explicar pelo mérito individual daqueles que a integram, dissimulando os fatores sociais que presidem à sua (re)produção. Por fim, num passo de reconciliação com Marx, todos estes elementos não deixam de ser enquadrados pelo "jogo das relações de exploração no capitalismo tardio".

\section{Referências bibliográficas}

Almeida, João Ferreira de, António Firmino da Costa, e Fernando Luís Machado (1994),

"Recomposição socioprofissional e novos protagonistas", em António Reis (org.),

Portugal, 20 Anos de Democracia, Lisboa, Círculo de Leitores, pp. 307-330. 
Bourdieu, Pierre (1979), La Distinction. Critique Sociale du Jugement, Paris, Les Editions de Minuit.

Costa, António Firmino da, e Rosário Mauritti (2018), “Classes sociais e inteseções de desigualdades: Portugal e a Europa", em Renato Miguel do Carmo et al. (orgs.), Desigualdades Sociais. Portugal e a Europa, Lisboa, Mundos Sociais, pp. 109-129.

Estanque, Elísio (2012), A Classe Média. Ascenção e Declínio, Lisboa, Fundação Francisco Manuel dos Santos.

Estanque, Elísio, e José Manuel Mendes (1997), Classes e Desigualdades Sociais em Portugal. Um Estudo Comparativo, Porto, Afrontamento.

Machado, Fernando Luís, e António Firmino da Costa (1998), “Processos de uma modernidade inacabada: mudanças estruturais e mobilidade social", em José Manuel Leite Viegas e António Firmino da Costa (orgs.), Portugal, Que Modernidade?, Oeiras, Celta Editora.

Mills, C. Wright (1951), White Collar. The American Middle Classes, Nova Iorque, Oxford University Press.

Mills, C. Wright (1956), The Power Elite, Nova Iorque, Oxford University Press.

Mills, C. Wright (2001 [1948]), The New Men of Power. America's Labor Leaders, Chicago, University of Illinois Press.

Pedro Abrantes. Professor da Universidade Aberta e investigador no Centro de Investigação e Estudos de Sociologia (CIES-Iscte), Iscte - Instituto Universitário de Lisboa, Lisboa, Portugal. E-mail: pedro.abrantes@iscte-iul.pt 